\title{
Quality of Life in Patients with Bladder Cancer Undergoing Ileal Conduit: A Comparison of Women Versus Men
}

\author{
SALVATORE SIRACUSANO $^{1 *}$, CAROLINA D'ELIA ${ }^{2 *}$, MARIA ANGELA CERRUTO ${ }^{1}$, OMAR SALEH $^{3}$, \\ SERGIO SERNI $^{3}$, MAURO GACCI ${ }^{3}$, STEFANO CICILIATO $^{4}$, ALCHIEDE SIMONATO ${ }^{5}$, ANTONIO PORCARO ${ }^{1}$, \\ VINCENZO DE MARCO ${ }^{1}$, RENATO TALAMINI ${ }^{6}$, LAURA TOFFOLI $^{4}$, FRANCESCO VISALLI $^{4}$, \\ MAURO NIERO $^{7}$, CRISTINA LONARDI $^{7}$, CIRO IMBIMBO $^{8}$, PAOLO VERZE $^{8}$, VINCENZO MIRONE $^{8}$, \\ MARCO RACIOPPI ${ }^{9}$, MASSIMO IAFRATE $^{10}$, GIOVANNI CACCIAMANI ${ }^{1}$, \\ DAVIDE DE MARCHI ${ }^{1}$, PIERFRANCESCO BASSI ${ }^{9}$ and WALTER ARTIBANI ${ }^{1}$ \\ ${ }^{1}$ Urology Department, and ${ }^{7}$ TESIS Department, University of Verona, Verona, Italy; \\ ${ }^{2}$ Urology Department, Bolzano General Hospital, Bolzano, Italy; \\ ${ }^{3}$ Urology Department, Careggi Hospital, University of Florence, Florence, Italy; \\ ${ }^{4}$ Urology Department, Trieste University, Trieste, Italy; \\ ${ }^{5}$ Department of Urology, IRCSS San Martino - IST, University of Genoa, Genoa, Italy; \\ ${ }^{6}$ Unit of Epidemiology and Biostatistics, IRCCS_CRO, Aviano, Italy; \\ ${ }^{8}$ Urology Department, University of Naples, Federico II, Naples, Italy; \\ ${ }^{9}$ Urology Department, Foudazione Policlinico Gemelli, Catholic University of Rome, Rome, Italy; \\ ${ }^{10}$ Urology Department, University of Padua, Padua, Italy
}

\begin{abstract}
Background/Aim: Studies comparing healthrelated quality of life $(H R-Q o L)$ between patients who underwent radical cystectomy $(R C)$ and those who underwent a different form of urinary diversion has not reached yet univocal and reliable conclusions. The aim of our study was to evaluate bladder-specific long-term HR-QoL after radical cystectomy and ileal conduit. Patients and Methods: A multicenter study was carried out on 145 consecutive patients (112 males and 33 females) undergoing $R C$ and ileal conduit (IC). HR-QoL assessment was conducted using Italian versions of European Organisation for Research and Treatment of Cancer QLQ-C30 and EORTC BLM-30 questionnaires. Results: Our data showed that women who underwent IC presented greater problems than men in cognitive functioning (mean score $\pm S D$ : $77.3 \pm 27.9 \mathrm{vs}$. 87.8 \pm 18.6 ) as well in future perspective (score: $42.4 \pm 34.4 \mathrm{vs}$.
\end{abstract}

This article is freely accessible online.

*These Authors contributed equally to this study.

Correspondence to: Carolina D'Elia, M.D, F.E.B.U., Ph.D., Urology Department, Bolzano General Hospital, Via Lorenz Bohler 9, 39100 Bolzano, Italy. Mobile +39 3496707889, Fax: +39 0458124080,e-mail: karolinedelia@gmail.com

Key Words: Bladder cancer, quality of life, ileal conduit, orthotopic neobladder, radical cystectomy.

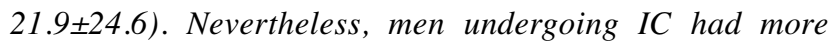
problems in sexual functioning than women (score: $23.3 \pm 24.5$ vs. 7.0 \pm 20.3$)$ (all p<0.05). Conclusion: In our series, female patients presented a greater burden than male patients in cognitive functioning as well in future perspective, but lower concerns with regard to sexual function.

Bladder cancer is one of the most commonly diagnosed types of cancer and Europe has the highest incidence rate of bladder cancer worldwide. Morevover, Spain and Italy have the highest incidence in men in Europe, at approximately 37/100,000 and 33/100,000. respectively, (1). Classically, according to European Association of Urology (EAU) Guidelines, radical cystectomy (RC) represents the gold standard treatment for muscle-invasive bladder cancer, T2T4a, N0-Nx, M0 and for high-risk and recurrent superficial tumours (2). Unfortunately, no consensus has been reached about ideal age, timing and type of urinary diversion after $\mathrm{RC}$. Options range from ileal conduit (IC) to orthotopic neobladder (ONB) reconstruction, with different outcomes, such as complication rates and health-related quality of life (HR-QoL). Studies comparing HR-QoL between radical cystectomy and different urinary diversion has not reached yet univocal and reliable conclusions. Nevertheless, in a recent meta-analysis of non-randomized comparative studies, Cerruto et al. demonstrated a significant advantage of ileal ONB compared to IC in terms of HR-QoL (3). On the other hand, a recent review conducted by Yang et al. failed to 
demonstrate a significant difference between patients after IC and ONB, even showing a small benefit for physical health with IC (4). According to Cerruto et al., findings regarding IC show patient satisfaction seems to be related to the degree of adaptation to their new life with an IC, a new phase of life and not simply a deterioration (5).

The aim of this study was to evaluate bladder-specific long-term HR-QoL after RC and IC and to assess whether HR-QoL outcomes differ between men and women.

\section{Patients and Methods}

A multicentre study was carried out on 145 consecutive patients (112 males and 33 females) undergoing RC and IC for bladder cancer at five Italian academic urological centres (Verona, Trieste, Naples Federico II, Padua and Rome Catholic University), from June 2007 to December 2013. Patients were invited to participate in the study at their follow-up medical consultation and gave their signed informed consent.

All the patients included in our study underwent RC and IC due to oncological indication and were affected by muscle-invasive bladder cancer or had non-responding high-grade non-muscleinvasive bladder cancer according to EAU Guidelines (2). Moreover, all patients underwent RC with pelvic and iliac lymph node dissection with radical en bloc cystectomy as described by Skinner and Lieskovsky (6), and were between 18-95 years of age, with a sufficient educational level and command of the italian language sufficient to understand and fill out a questionnaire. Patients who were not capable of completing a questionnaire, or had a history of psychiatric disorders, alcohol or substance abuse, difficulties in verbal or written communication, non-Italian speakers, as well as those who had cognitive deterioration, were excluded from the study. Moreover, all the included patients had no evidence of disease recurrence and were actively followed-up.

Data obtained from the retrospective review included age, gender, follow-up (months), pathological tumour (pTNM) stage as defined by the Union for International Cancer Control (UICC) (7), grading, and adjuvant chemo- or radiotherapy. All these clinical, pathological as well as clinical outcome data were retrospectively analyzed and a comprehensive database was created.

HRQoL assessment was conducted using italian versions of EORTC QLQ-C30 and EORTC BLM-30 questionnaires (8).

The study was approved by local Ethics Committees at each center.

Quality of life assessment. Patients were asked to complete both the following questionnaire: i) The EORTC-QLQ-C30 is a 30-item cancer-specific validated questionnaire, the most known tool for the QoL assessment. The versions we used were culturally validated in the italian language (male/female Italian version) and subjected to psychometric validation. This 30 -item questionnaire has multi-item scales and single items reflecting the multidimensionality of the QoL construct. It comprises five functional scales covering physical, role, emotional, cognitive and social aspects, and one scale of global health status/QoL. It also includes three multi-item symptom scales of fatigue, nausea/vomiting and pain, and six single items that deal with dyspnoea, insomnia, appetite loss, constipation, diarrhoea and financial difficulties caused by the disease or its treatment. The scores obtained were converted into a scale from 0 to 100 according to the provisions of the EORTC manual: aiming to obtain more useful and easily understandable statistical data. For functional and overall scales, higher scores represent a better QoL outcome, whereas for symptom and single-item scales, higher scores correspond to more problems and a reduced QoL.

ii) The EORTC-QLQ-BLM30 (specific for muscle-invasive bladder cancer) is a module from the EORTC that specifically evaluates the impact of RC and reconstructive surgery in terms of HR-QoL. It is a 30-item questionnaire that includes questions related to general symptoms for all patients, a specific section with questions for patients with urinary diversion, questions on sexual function and a series of questions on the emotional state. For symptoms/single items, a higher score means a higher level of symptoms/problems. There is still no psychometric validation for this questionnaire and Italian linguistic validation has not been performed yet.

Statistical analysis. Statistical analyses were conducted using SAS version 9.3 software (SAS Institute, Inc., Cary, NC, USA). Mean values with standard deviations $( \pm \mathrm{SD})$ were computed and reported for age (years), follow-up (months), and for all items included in the EORTC.

Wilcoxon two-sample test was used to verify differences between continuous variables, whereas Chi-square test was used to compare categorical variables.

Statistical significance was achieved when the two-sided $p$-value was 0.05 or less.

\section{Results}

This multicentric study was conducted on 145 patients (112 males and 33 females) who underwent $\mathrm{RC}$ and IC in five urological academic centres. Patient characteristics are reported in Table I.

The two groups were comparable with regard to the clinical and demographical variables.

The EORTC- QLQ C30 data regarding our series are reported in Table II, and those for EORTC-QLQ BLM-30 are reported in Table III.

Our data showed that women with IC presented significantly greater problems than men in cognitive functioning (higher score means better functionally: $77.3 \pm 27.9$ vs. 87.8 \pm 18.6 , respectively, $p=0.04$ ) as well in future perspective (lower score means a low level of symptomatology/problems: $42.4 \pm 34.4 \mathrm{vs}$. 21.9 \pm 24.6 , respectively, $p=0.001$ ). Nevertheless, men undergoing IC had more problems in sexual functioning than women $(23.3 \pm 24.5 v s .7 .0 \pm 20.3$, respectively, $p=0.001)$.

\section{Discussion}

In 1948, the World Health Organization defined health as being not only the absence of disease and infirmity, but also the presence of physical, mental and social well-being (9). Nevertheless. according to this definition, HR-QoL refers to a multidimensional concept, including physical, social and psychological wellbeing of the person, changing over time and influenced by expectations, concerns and experiences. 
Table I. Centre, age and pathological and clinical characteristics of 145 patients with ileal conduit according to gender.

\begin{tabular}{|c|c|c|c|}
\hline Characteristic & Males & Females & $p$-Value ${ }^{\mathrm{a}}$ \\
\hline No. of patients & 112 & 33 & \\
\hline \multicolumn{4}{|l|}{ Centre, $\mathrm{n}(\%)$} \\
\hline Naples & $30(26.8)$ & $2(6.1)$ & \\
\hline Padua & $16(14.3)$ & $7(21.2)$ & \\
\hline Rome & $25(22.3)$ & $5(15.1)$ & \\
\hline Trieste & $15(13.4)$ & $6(18.2)$ & \\
\hline Verona & $26(23.2)$ & $13(39.4)$ & ns \\
\hline Mean age $( \pm \mathrm{SD})$, years & $71.0( \pm 8.2)$ & $70.5( \pm 8.7)$ & ns \\
\hline Mean follow-up $( \pm$ SD), months & $41.8( \pm 34.4)$ & $52.5( \pm 40.5)$ & $\mathrm{ns}$ \\
\hline \multicolumn{4}{|c|}{ Stage (pTNM-UICC), n (\%) } \\
\hline Stage 0 -I & $38(33.9)$ & $11(33.3)$ & \\
\hline Stage II & $34(30.4)$ & $7(21.2)$ & \\
\hline Stage III+IV & $40(35.7)$ & $15(45.5)$ & $\mathrm{ns}$ \\
\hline \multicolumn{4}{|l|}{ Grading, $\mathrm{n}(\%)$} \\
\hline Gx & $1(0.9)$ & -- & \\
\hline G1-2 & $8(7.1)$ & $2(6.1)$ & \\
\hline G3-4 & $103(92.0)$ & $31(93.9)$ & $\mathrm{ns}$ \\
\hline \multicolumn{4}{|l|}{ Adjuvant chemotherapy, n (\%)* } \\
\hline No & $84(77.8)$ & $25(75.8)$ & \\
\hline Yes & $24(22.2)$ & $8(24.2)$ & $\mathrm{ns}$ \\
\hline \multicolumn{4}{|l|}{ Adjuvant radiotherapy, $\mathrm{n}(\%) *$} \\
\hline No & $102(92.7)$ & $32(97.0)$ & \\
\hline Yes & $8(7.3)$ & $1(3.0)$ & $\mathrm{ns}$ \\
\hline
\end{tabular}

*Totals may not agree due to missing values. aWilcoxon two-sample test or Chi-square test were used as appropriate (females vs. males). SD: standard deviation; ns: not significant $(p>0.05)$.

Every perturbance of the health status has a major impact on a patient's daily and personal life, leading to difficulty in social and working activities and to frustration. The duty of care of physicians is not limited to obtaining physical health, but also concerns maintaining a patient's capacity to fulfill family, social and working roles.

The urological literature emphasizes the importance of HRQoL in patients undergoing RC and urinary diversion; the ideal form of urinary diversion after RC should be easy to handle, presenting few complications, with low mortality and morbidity, protecting upper urinary tract function and e the ensuring the best possible HRQoL. Unfortunately, only few studies have compared HRQoL between female and male patients undergoing $\mathrm{RC}$, who present different types of postoperative complications and impact on daily and personal life.

In our series, at a mean ideal follow-up of 40 months, well after the time for stabilization of QoL hypothesized by Kulaksizoglu et al. (12 months), female patients undergoing $\mathrm{RC}$ and IC showed a more severe impact on cognitive function and future perspective, but a lower burden on their sexual life (10). Our results on sexual life in patients with IC agree with the literature data.
Table II. Mean and standard deviation $( \pm S D)$ of scores for the $Q L Q$ C30 functional and single items according to gender of 145 patients with ileal conduit.

\begin{tabular}{|c|c|c|c|}
\hline Item & $\begin{array}{c}\text { Males } \\
(\mathrm{N}=112) \\
\text { Mean }( \pm \mathrm{SD})\end{array}$ & $\begin{array}{c}\text { Females } \\
(\mathrm{N}=33) \\
\text { Mean }( \pm \mathrm{SD})\end{array}$ & $p$-Value ${ }^{a}$ \\
\hline Physical functioning* & $73.9( \pm 25.2)$ & $75.4( \pm 24.0)$ & ns \\
\hline Role functioning* & $78.4( \pm 28.9)$ & $72.2( \pm 29.4)$ & $\mathrm{ns}$ \\
\hline Emotional functioning* & $80.5( \pm 23.0)$ & $72.7( \pm 30.1)$ & ns \\
\hline Cognitive functioning* & $87.8( \pm 18.6)$ & $77.3( \pm 27.9)$ & 0.04 \\
\hline Social functioning* & $84.7( \pm 22.8)$ & $80.3( \pm 23.7)$ & $\mathrm{ns}$ \\
\hline Fatigue ${ }^{\S}$ & $29.1( \pm 26.6)$ & $31.0( \pm 30.1)$ & ns \\
\hline Nausea and vomiting§ & $5.2( \pm 14.5)$ & $2.5( \pm 7.4)$ & ns \\
\hline Pain§ & $11.8( \pm 17.6)$ & $13.1( \pm 21.1)$ & ns \\
\hline Dyspnoea ${ }^{\S}$ & $20.5( \pm 26.2)$ & $21.2( \pm 31.0)$ & ns \\
\hline Insomnia ${ }^{\S}$ & $19.3( \pm 27.8)$ & $22.2( \pm 27.2)$ & ns \\
\hline Appetite loss $\S$ & $15.2( \pm 28.3)$ & $12.1( \pm 26.1)$ & ns \\
\hline Constipation $\S$ & $33.3( \pm 34.7)$ & $27.3( \pm 35.8)$ & ns \\
\hline Diarrhoea $^{\S}$ & $8.6( \pm 20.4)$ & $10.1( \pm 27.0)$ & ns \\
\hline Financial difficulties $\S$ & $15.6( \pm 26.8)$ & $10.1( \pm 17.6)$ & ns \\
\hline Global quality of life scale§ & $62.5( \pm 24.3)$ & $60.9( \pm 29.2)$ & ns \\
\hline
\end{tabular}

*A higher score represents a higher level of functioning. ${ }^{\S}$ A higher score means a higher level of symptomatology/problems. ${ }^{a}$ Wilcoxon twosample test (females $v s$. males). Ns: not significant $(p>0.05)$.

Table III. Mean and standard deviation $( \pm S D)$ of scores for the $Q L Q$ BLM30 items according to gender of 145 patients with ileal conduit.

\begin{tabular}{lccc}
\hline Item & $\begin{array}{c}\text { Males } \\
(\mathrm{N}=112) \\
\text { Mean }( \pm \mathrm{SD})\end{array}$ & $\begin{array}{c}\text { Females } \\
(\mathrm{N}=33) \\
\text { Mean }( \pm \mathrm{SD})\end{array}$ & $p$-Value \\
\hline $\begin{array}{l}\text { Future perspective } \S \\
\begin{array}{l}\text { Abdominal bloating } \\
\text { and flatulence }\end{array}\end{array}$ & $21.9( \pm 24,6)$ & $42.4( \pm 34.4)$ & 0.001 \\
$\begin{array}{l}\text { Body image§ } \\
\text { Sexual functioning }\end{array}$ & $24.7( \pm 24.9)$ & $26.3( \pm 31.5)$ & $\mathrm{ns}$ \\
Sex life $^{8}$ & $29.6( \pm 28.8)$ & $28.3( \pm 33.1)$ & $\mathrm{ns}$ \\
\hline & $23.3( \pm 24.5)$ & $7.0( \pm 20.3)$ & 0.001 \\
& $80.8( \pm 33.7)$ & $75.0( \pm 50.0)$ & $\mathrm{ns}$ \\
\hline
\end{tabular}

$\S$ A higher score means a higher level of symptomatology/problems. aWilcoxon two-sample test (females $v s$. males). Ns: not significant $(p>0.05)$.

In 2004, Protogerou et al. evaluated 108 recurrence-free patients undergoing $\mathrm{RC}$ and IC and S-pouch (with a control group) using the EORTC- QLQ C30 questionnaire. The patients of the IC group reported worse urinary function, but sexual dysfunction, similar for the groups, was less important in women compared with the male population (11), as reported in our series. These data were confirmed by Hedgepeteh et al., who evaluated 336 patients undergoing $\mathrm{RC}$ and IC or ONB or simple cystoscopy using the Bladder Cancer Index (12) and the EORTC Body Image Scale (13). 
They documented higher sexual functional scores in female patients $(p=0.021)$ and generally worse for patients with conduit (14).

In our study, women reported better sexual function in comparison with male patients; female sexual function may be influenced by body perception and changes in body image, whereas male patients may experience problems in erectile function and ejaculatory function (15). The absence of ejaculation, obviously affecting only male patients, can deeply affect sexual QoL of the patients, as documented by Mak et al., comparing patients affected by muscle-invasive bladder cancer and treated with RC or bladder-sparing trimodal therapy (15).

Moreover, in 2006, Allareddy et al. evaluated QoL in long-term surviving patients undergoing RC using the Functional Assessment of Cancer Therapy (FACT-BL) instrument (16). At multivariate analysis, male patients had globally higher QoL life scores in comparison with female patients, but male patients had a worse social and well-being score in the stage II population (17).

With regard to the concerns about future and cognitive function, no literature studies documented differences between male and female patients; nevertheless, Cerruto et $a l$, in a systematic review of QoL after RC, showed that study populations with more than $65 \%$ of men had a better HR-QoL, but only in the ONB subgroup (5).

Although not significant, $45 \%$ of the female patients $v s$. $35 \%$ of the male patients had clinical stage III-IV disease, which can negatively influence QoL and concerns about future perspective and future disease recurrence in this population.

Our study presents several biases: a relatively limited number of patients, although our findings agree with literature data, and the absence of a baseline evaluation; nevertheless, the use of validated questionnaires make our results reliable and comparable.

Larger and prospective studies using validated questionnaires are needed, with the aim of easily comparing QoL between men and women undergoing RC; in addition, the use of specific questionnaires, such as the IONB-PRO, should be encouraged in order to address the specific problems and concerns related to the type of urinary diversion (18).

\section{Conclusion}

In our series of 145 patients undergoing IC, female patients present greater burden than male patients in cognitive functioning, as well in future perspective, but lesser concerns with regard to sexual function. Larger and randomized studies are needed, with the aim of better understanding the aetiology of these differences.

\section{Conflict of Interest}

The Authors declare that they have no conflict of interest.
All procedures performed in studies involving human participants were in accordance with the ethical standards of the institutional and/or national research committee and with the 1964 Helsinki declaration and its later amendments or comparable ethical standards.

Informed consent was obtained from all individual participants included in the study.

\section{References}

1 Antoni S, Ferlay J, Soerjomataram I, Znaor A, Jemal A and Bray F: Bladder cancer incidence and mortality: a global overview and recen trends. Eur Urol 71: 96-108, 2017.

2 Babjuk M, Burger M, Zigeuner R, Shariat SF, van Rhijn BW, Compérat E, Sylvester RJ, Kaasinen E, Böhle A, Palou Redorta J, Rouprêt M: European Association of Urology EAU guidelines on non-muscle invasive urothelial carcinoma of the bladder: update 2013. Eur Urol 64: 639-653, 2013.

3 Cerruto MA, D'Elia C, Siracusano S, Gedeshi X, Mariotto A, Iafrate, Niero M, Lonardi C, Bassi P, Belgrano E, Imbimbo C, Racioppi M, Talamini R, Ciciliato S, Toffoli L, Rizzo M, Visalli F, Verze P and Artibani W: Systematic review and meta-analysis of non RCTs on health related quality of life after radical cystectomy using validated questionnaires: Better results with orthotopic neobladder versus ileal conduit. Eur J Surg Oncol 42: 343-360, 2016.

4 Yang LS, Shan BL, Shan LL, Chin P, Murray S, Ahmadi N and Saxena A: A systematic review and meta-analysis of quality of life outcomes after radical cystectomy for bladder cancer. Surg Oncol 25: 281-297, 2016.

5 Cerruto MA, D'Elia C, Cacciamani G, De Marchi D, Siracusano S, Iafrate M, Niero M, Lonardi C, Bassi P, Belgrano E, Imbimbo C, Racioppi M, Talamini R, Ciciliato S, Toffoli L, Rizzo M, Visalli F, Verze $\mathrm{P}$ and Artibani $\mathrm{W}$ : Behavioural profile and human adaptation of survivors after radical cystectomy and ileal conduit. Health Qual Life Outcomes 12: 46, 2014.

6 Skinner DG and Lieskovsky G: Management of invasive highgrade bladder cancer. In: Diagnosis and Management of Genitourinary Cancer. Philadelphia: WB Saunders Co. vol 1, pp. 295-324, 1987.

7 Sobin LH, Gospodarowicz MK and Wittekind C: TNM Classification of Malignant Tumours, Seventh Edition. New York: Wiley-Liss, 2010.

8 Aaronson NK, Ahmedzai S, Bergman B, Bullinger M, Cull A, Duez NJ, Filiberti A, Flechtner H, Fleishman SB, de Haes JC: The European Organization for Research and Treatment of Cancer QLQ-C30: a quality-of-life instrument for use in international clinical trials in oncology. J Natl Cancer Inst 85: 365-376, 1993.

9 World Health Organization. Available at http://www.who.int

10 Kulaksizoglu H, Toktas G, Kulaksizoglu IB, Aglamis E, Unlüer E: When should quality of life be measured after radical cystectomy? Eur Urol. 4: 350-355, 2002.

11 Protogerou V, Moschou M, Antoniou N, Varkarakis J, Bamias A and Deliveliotis C: Modified S-pouch neobladder vs. ileal conduit and a matched control population: a quality-of-life survey. BJU Int 94: 350-354, 2004.

12 Gilbert SM, Wood DP, Dunn RL, Weizer AZ, Lee CT, Montie JE and Wei JT: Measuring health-related quality of life outcomes in bladder cancer patients using the Bladder Cancer Index (BCI). Cancer 109: 1756-1762, 2007. 
13 Hopwood P, Fletcher I, Lee A, Al Ghazal S: A body image scale for use with cancer patients. Eur J Cancer 37: 189-197, 2001.

14 Hedgepeth RC, Gilbert SM, He C, Lee CT, Wood DP Jr.: Body image and bladder cancer specific quality of life in patients with ileal conduit and neobladder. Urinary Diversions Urol 76: 671676, 2010

15 Mak KS, Smith AB, Eidelman A, Clayman R, Niemierko A, Cheng JS, Matthews J, Drumm MR, Nielsen ME, Feldman AS, Lee RJ, Zietman AL, Chen RC, Shipley WU, Milowsky MI and Efstathiou JA: Quality of life in long-term survivors of muscleinvasive bladder cancer. Int J Radiat Oncol Biol Phys 96: 10281036, 2016.

16 Cella DF, Tulsky DS, Gray G, Sarafian B, Linn E, Bonomi A, Silberman M, Yellen SB, Winicour $\mathrm{P}$ and Brannon J: The Functional Assessment of Cancer Therapy scale: development and validation of the general measure. J Clin Oncol 11: 570-579, 1993.
17 Allareddy V, Kennedy J, West MM and Konety BR: Quality of life in long-term survivors of bladder cancer. Cancer 106: 23552362, 2006.

18 Siracusano S, Niero M, Lonardi C, Cerruto MA, Ciciliato S, Toffoli L, Visalli F, Massidda D, Iafrate M, Artibani W, Bassi P, Imbimbo C, Racioppi M, Talamini R, D'Elia C, Cacciamani G, De Marchi D, Silvestri T, Verze P and Belgrano E: Development of a questionnaire specifically for patients with ileal orthotopic neobladder (IONB). Health Qual Life Outcomes 12: 135, 2014.

Received October 16, 2017

Revised November 19, 2017

Accepted November 29, 2017 